\title{
A matched case-control study of risk factors associated with multiple sclerosis in Kuwait
}

\author{
Hadeel El-Muzaini ${ }^{1 *} \mathbb{D}$, Saeed Akhtar $^{1}$ and Raed Alroughani ${ }^{2}$
}

\begin{abstract}
Background: Genetic and environmental factors seem to have etiologic roles in multiple sclerosis (MS). Kuwait is regarded as medium to high risk country for MS. However, there is a paucity of published data on the risk factors for MS in Kuwait. Therefore, this matched case-control study examined the association between various factors including family history, stressful life events, exposure to tobacco smoke, vaccination history, comorbidities and MS risk in Kuwait.

Methods: Confirmed 110 MS cases and age ( \pm 5 years), gender and nationality matched controls (1:1) were enrolled. A pre-tested structured questionnaire was used to collect the data through face-to-face interviews both from cases and controls. Conditional logistic regression was used to analyze the data.

Results: Among both cases and controls, majority were Kuwaiti (82.7\%), and female (76.4\%). Multivariable model showed that cases compared to controls were significantly more likely to have had a family history of MS (adjusted matched odds ratio $\left.\left(\mathrm{mOR}_{\mathrm{adj}}\right)=5.1 ; 95 \% \mathrm{Cl}: 2.1-12.4 ; p<0.001\right)$ or less likely to have been vaccinated against influenza $A$ and $B$ viruses before $M S$ onset $\left(\mathrm{mOR}_{\mathrm{adj}}=0.4 ; 95 \% \mathrm{Cl}: 0.2-0.8 ; p=0.010\right)$. None of the other variables considered were significantly related to MS status in this study.

Conclusions: Family history of MS had significantly direct, whereas, vaccination against influenza A and B viruses had inverse associations with MS status. Future studies may contemplate to verify the observed results.
\end{abstract}

Keywords: Multiple sclerosis, Family history, Matched case-control study, Conditional logistic regression, Middle-east

\section{Introduction}

Multiple sclerosis (MS) is a chronic inflammatory neurological disorder that affects young adults, causing a range of morbidities and disabilities [1-3]. Globally, the estimated number of people with MS has increased from 2.1 million in 2008 to 2.3 million in 2013 [4], with higher prevalence in females [1]. Also, in Kuwait the sex ratio (female: male) of 1.9 among MS cases has been reported $[5,6]$. The precise etiology of MS continues to be undefined. However, epidemiological studies have suggested that environmental exposures of genetically susceptible individuals play an important role in the causation of MS. Additionally, family history, ethnicity, viral infections mainly Epstein-Barr virus

\footnotetext{
* Correspondence: hmuz@hsc.edu.kw

${ }^{1}$ Department of Community Medicine and Behavioural Sciences, Faculty of

Medicine, University of Kuwait, PO Box 24923, 13110 Safat, Kuwait

Full list of author information is available at the end of the article
}

(EBV), vitamin D deficiency, geographic location have been shown to be the risk factors for MS [1]. Month of birth has been shown to increase MS risk in different countries, which might be associated with varying length of exposure to sunlight and perhaps resulting in vitamin D deficiency $[1,7,8]$. Smoking including its dose and duration have been shown to be associated with increased MS risk [1, 9-12], disease progression $[1,13]$, and excess mortality among MS patients [14].

Kuwait experienced an increase in MS incidence (per 100,000 population), during 1993 (1.1), 2000 (2.6), 2011 (6.9) and the corresponding MS prevalence (per 100,000 population) of $6.7,14.8$ and 85.1 for these years respectively $[15,16]$. Advocated plausible explanations for the increased MS burden in Kuwait include public awareness, socioeconomic status changes, adoption of revised versions of diagnostic criteria, better ascertainment of 
the cases, increased number of neurologists and availability of magnetic resonance imaging (MRI) and other diagnostic tests, in addition to the introduction of the national MS registry [16]. Moreover, environmental exposures [3,7], changing lifestyle and dietary patterns of Kuwaiti populations have been implicated [3]. Parenthetically the prevalence of tobacco smoking is very high (20.5\%) in Kuwait [17], and practiced both by smoking cigarettes and waterpipe [18]. In Kuwait, a large proportion of adolescents (13-15 years) also get exposed to tobacco smoke through various modes including active cigarette smoking (21.1\%), waterpipe use $(16.2 \%)$ and/ or through exposure to secondhand tobacco smoke (42.9\%). However, few studies conducted in Kuwait showed nonsignificant relationship between tobacco smoking and MS risk $[3,7]$, which warranted further investigations. Furthermore, concurrent comorbidities and vaccinations against viral infections suspected to contribute to MS risk also need to be explored in the settings of the Middle Eastern countries including Kuwait. Therefore, this matched casecontrol study was sought to examine the association between various potential risk factors and MS risk in Kuwait.

\section{Participants and methods}

\section{Study design and setting}

A matched case-control design was implemented to address the objective of this study. Cases were enrolled from neurology clinics at Ibn Sina Hospital and MS clinic at Dasman Diabetes Institute. These are the only two neurology clinics which deal with confirmatory diagnosis and treatment of MS cases in Kuwait. Cases suspected for MS seen in any other clinics/ hospitals in Kuwait are referred to one of these two clinics (our study sites) for confirmatory diagnosis and treatment. Subsequently confirmed MS cases are registered in Kuwait National MS Registry. Controls were selected from among the staff and students of the Kuwait University. University staff included academic members, administrative and secretarial staff. This is the only public-sector university in the country, offering free education to all enrolled students. Therefore, it was assumed that faculty, staff and enrolled students represent the typical Kuwaiti population.

\section{Case definition, inclusion and exclusion criteria}

A case was defined as a patient of any age, gender, nationality and resident of Kuwait with a confirmed MS, diagnosed by a neurologist using the revised 2010 McDonald Criteria [19]. Individuals with cognitive impairment or any neurological disease other than MS were excluded. Resident status in Kuwait indicates that the person is not a short-term visitor. Resident status defines that the person is either a Kuwaiti citizen or a migrant worker (with work permit) including dependent(s) of a migrant worker.

\section{Control definition, inclusion and exclusion criteria}

A control was defined as a resident of Kuwait without prior history of confirmed MS diagnosis. Controls were individually matched with each case for age ( \pm 5 years), gender and nationality. Each control was given a date of pseudo-onset of MS which matched with the date of onset of corresponding MS case. Individuals with poor cognitive ability or any past or present neurological disease were excluded.

\section{Questionnaire development and data collection}

A face-to-face interview of each case and his/ her pair matched control was conducted using a structured questionnaire to collect the data on socio-demographic, potential genetic and environmental factors identified through literature review [3, 9]. Enrollment of cases and controls was carried out from July 1, 2016 to September 30, 2016. Date of MS onset was labelled as index year and history of potential exposures were assessed prior to the end of that year. Similarly, in the matched control a date of pseudo-onset of MS was constructed, which is the date of MS onset of the case. Control subjects were asked to report their exposures prior to the end of the index year (i.e. year of their pseudo-onset of MS). Questions on socio-demographic factors included age (completed years), gender, nationality, place of birth, birth order, number of siblings and relationship of parents. Participants were asked about their education level, occupation, family income, marital status and governorate of residence at the time of MS onset, and history of all countries lived in prior to disease. Age (completed years), self-reported height and weight at time of MS onset were recorded. History of vaccination, presence of other disease(s), head trauma, and self-reported vitamin D status was taken. Assessment of genetic and environmental exposures included family history of MS and other diseases including autoimmune diseases (inflammatory bowel disease, systemic lupus erythematosus, rheumatoid arthritis, Graves' disease), presence in Kuwait during first Gulf war of 1990, history of exposure to solvents and vaccinations' history. History of exposure to tobacco smoke and secondhand smoking was obtained from cases and controls, by asking about previous smoking status [20, 21]. Exposure to tobacco smoke for the period prior to MS onset/pseudo-onset was assessed both in cases and controls respectively. Data were gathered on average number of cigarettes/waterpipes smoked, frequency and duration of tobacco smoking. Subsequently the amount of tobacco smoked over a period of interest was calculated as pack-years. Data on exposure to secondhand smoking was obtained, by asking participants if they have been exposed to tobacco smoke at home or elsewhere. Approximate duration (years) of secondhand smoking was calculated. The questionnaire was pretested and modified if required before 
actual use in the study. The final study questionnaire can be found as a Additional files 1 and 2 .

\section{Sample size}

By taking into account $10 \%$ potential non-response and to achieve a statistical power $(1-\beta)$ of $80 \%$, this matched case-control study was designed to enroll 100 patients with MS and 100 MS-free matched controls (1:1 ratio) to relate most of the potential exposures (having a prevalence 0.25 or higher in the general population) and MS status with a matched odds ratio (mOR) 2.5 or higher using conditional logistic regression at a $5 \%$ significance level $(\alpha)[22]$.

\section{Ethics}

Written consent was obtained from each study participant after explaining the aims and potential benefits of the study, length of questionnaire and time required to answer all the questions. Ethical approval of the study protocol was granted by Health Sciences Center Ethical Committee, Kuwait University and The Standing Committee for Coordination of Health and Medical Research, Ministry of Health, Kuwait.

\section{Statistical analysis}

Descriptive statistics including means and standard deviations of quantitative variables and frequencies (\%) of qualitative variables were computed. Variables significantly $(p \leq 0.15)$ related with MS status on univariable conditional logistic regression analysis were considered for their possible inclusion in the final multivariable conditional logistic regression model. The variables significantly $(p<0.05)$ and independently associated with MS status were retained in the final model. Adjusted mOR ( $\mathrm{mOR}_{\mathrm{adj}}$ ) and their 95\% confidence intervals $(\mathrm{CI})$, were calculated from the parameter estimates of the final model. Statistical analyses were performed using Stata 14.2. (College Station, TX: StataCorp LP).

\section{Results}

\section{Characteristics of case and control samples}

In this case-control study, $112 \mathrm{MS}$ cases were invited to participate and 110 (98.2\%) consented for enrollment. One hundred and ten MS cases and 110 control subjects, individually matched with cases (1:1) on age ( \pm 5 years), gender and nationality were enrolled (Fig. 1). The mean (SD) age (years) was 34.8 (10.3) and 34.9 (10.6) for cases and controls respectively. The mean (SD) age was 27.3 (9.0) years was nearly the same at the time of MS onset in cases or pseudo-onset in controls. Both in cases and controls, $82.7 \%$ were Kuwaiti nationals and $76.4 \%$ were females. The distributions of demographic characteristics such as marital status, monthly income (KD), governorate of residence and relative distributions of potential risk factors in cases and controls are shown in Tables 1 and 2 respectively.

\section{Univariable conditional logistic regression analyses}

Univariable conditional logistic analyses showed that cases were significantly more likely to have positive family history of MS $(p=0.002)$ or less likely to receive influenza virus A and $\mathrm{B}$ vaccine $(p=0.030)$. However, cases compared to

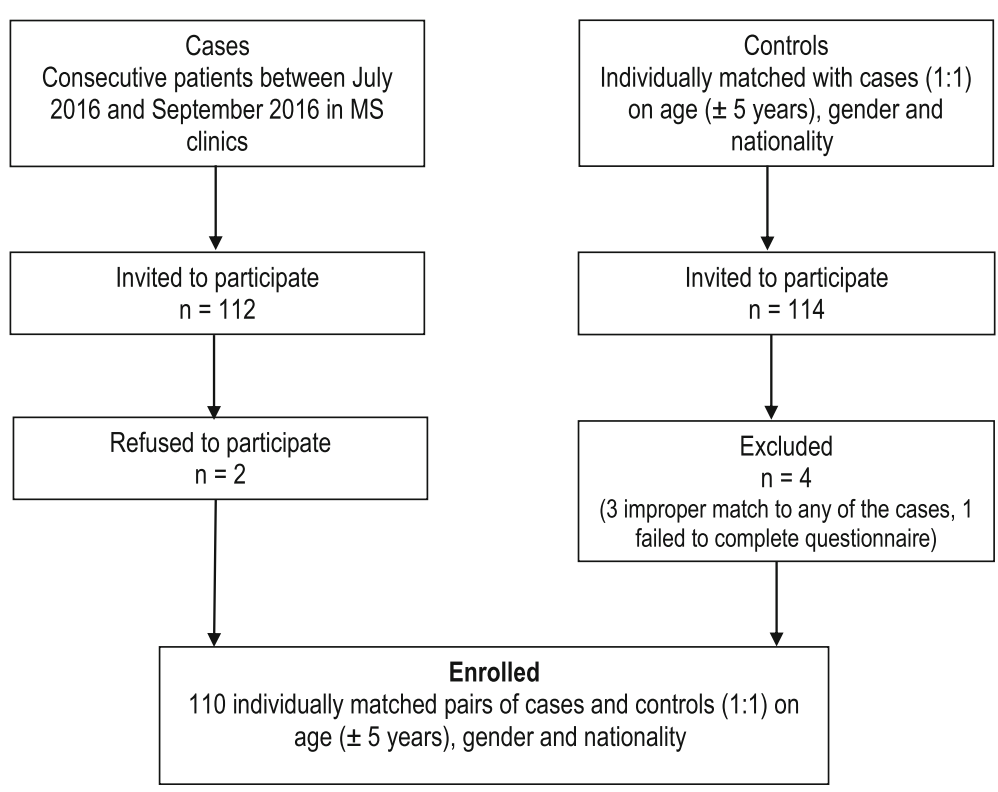

Fig. 1 Flow chart describing the enrollment of the MS cases and controls 
Table 1 Socio-demographic characteristics of cases and controls enrolled in a case-control study of risk factors for multiple sclerosis in Kuwait

\begin{tabular}{|c|c|c|}
\hline \multirow[t]{2}{*}{ Characteristics } & \multirow{2}{*}{$\begin{array}{l}\text { MS patients } \\
\left(\mathrm{N}_{1}=110\right) \\
\mathrm{n}_{1}(\%)\end{array}$} & \multirow{2}{*}{$\begin{array}{l}\text { Controls } \\
\left(\mathrm{N}_{2}=110\right) \\
\mathrm{n}_{2}(\%)\end{array}$} \\
\hline & & \\
\hline \multicolumn{3}{|l|}{ Current age (years) } \\
\hline$<20$ & $8(7.3)$ & $4(3.6)$ \\
\hline $20-29$ & $28(25.5)$ & $34(30.9)$ \\
\hline $30-39$ & $43(39.1)$ & $40(36.4)$ \\
\hline $40-49$ & $19(17.3)$ & 19 (17.3) \\
\hline$\geq 50$ & $12(10.9)$ & $13(11.8)$ \\
\hline Mean (SD) & $34.8(10.3)$ & $34.9(10.6)$ \\
\hline Age (years) at MS onset Mean (SD) & $27.3(9.0)$ & $27.3(9.0)$ \\
\hline \multicolumn{3}{|l|}{ Gender } \\
\hline Male & $26(23.6)$ & $26(23.6)$ \\
\hline Female & $84(76.4)$ & $84(76.4)$ \\
\hline \multicolumn{3}{|l|}{ Nationality } \\
\hline Kuwaiti & $91(82.7)$ & $91(82.7)$ \\
\hline Non-Kuwaiti & 19 (17.3) & 19 (17.3) \\
\hline \multicolumn{3}{|l|}{ Country of birth } \\
\hline Kuwait & $98(89.1)$ & $103(93.6)$ \\
\hline Abroad & $12(10.9)$ & $7(6.4)$ \\
\hline \multicolumn{3}{|l|}{ Marital status at MS onset } \\
\hline Never married & $54(49.1)$ & $61(55.5)$ \\
\hline Ever married & $56(50.9)$ & $49(44.5)$ \\
\hline \multicolumn{3}{|l|}{ Income (KD/month) at MS onset } \\
\hline$\leq 600$ & $13(12.4)$ & $13(12.0)$ \\
\hline $601-1200$ & $25(23.8)$ & $24(22.2)$ \\
\hline$>1201$ & $67(63.8)$ & $71(65.7)$ \\
\hline \multicolumn{3}{|l|}{ Area of residence } \\
\hline Capital & $30(27.5)$ & $22(20.0)$ \\
\hline Hawalli & $36(33.0)$ & $53(48.2)$ \\
\hline Farwaniya & $13(11.9)$ & $7(6.4)$ \\
\hline Ahmadi & $8(7.3)$ & $11(10.0)$ \\
\hline Jahra & $4(3.7)$ & $7(6.4)$ \\
\hline Mubarak Al Kabeer & $18(16.5)$ & $10(9.1)$ \\
\hline
\end{tabular}

their matched controls were not statistically significantly different in terms of active or passive tobacco smoking, number of siblings, parent's relationship, presence in Kuwait during first Gulf war of 1990, history of tonsillectomy and appendectomy. Also, distributions of selfreported vitamin D deficiency, area of residency, history of chickenpox, mumps and measles infections, regular exposure to solvents, vaccination status against hepatitis B virus and measles-mumps-rubella viruses were not statistically significantly different between MS cases and their matched controls (Table 3).
Table 2 Distribution of potential risk factors in cases and controls enrolled in a case-control study of risk factors for multiple sclerosis in Kuwait

\begin{tabular}{|c|c|c|}
\hline Characteristics & $\begin{array}{l}\text { MS patients } \\
\left(\mathrm{N}_{1}=110\right) \\
\mathrm{n}_{1}(\%)\end{array}$ & $\begin{array}{l}\text { Controls } \\
\left(\mathrm{N}_{2}=110\right) \\
\mathrm{n}_{2}(\%)\end{array}$ \\
\hline \multicolumn{3}{|l|}{$\overline{\mathrm{BMI}}$} \\
\hline$<25$ & $50(50.0)$ & $54(52.4)$ \\
\hline $25-29.9$ & $28(28.0)$ & $28(27.2)$ \\
\hline$\geq 30$ & $22(22.0)$ & $21(20.4)$ \\
\hline $\begin{array}{l}\text { Education level at MS diagnosis } \\
\text { ( } \leq \text { high school vs. }>\text { high school level) }\end{array}$ & $29(26.4)$ & $19(17.3)$ \\
\hline Birth order (1st/2nd or more) & $24(21.8)$ & $26(23.6)$ \\
\hline \multicolumn{3}{|l|}{ Parents' relationship } \\
\hline Unrelated & $80(72.7)$ & $73(66.4)$ \\
\hline First degree cousins & $22(20.0)$ & $21(19.1)$ \\
\hline Second degree cousins & $8(7.3)$ & $16(14.5)$ \\
\hline Presence during Gulf war (yes/no) & $59(53.6)$ & $71(64.5)$ \\
\hline Family history of MS (yes/no) & $33(30.0)$ & $13(11.8)$ \\
\hline Tobacco smoking (yes/no) & $18(16.4)$ & $12(10.9)$ \\
\hline $\begin{array}{l}\text { Childhood exposure to environmental } \\
\text { tobacco smoke (yes/no) }\end{array}$ & $47(42.7)$ & $56(50.9)$ \\
\hline Regular passive smoking (yes/no) & $67(62.0)$ & $69(62.7)$ \\
\hline Tonsillectomy before MS onset (yes/no) & $10(9.1)$ & $9(8.2)$ \\
\hline Appendectomy before MS onset (yes/no) & $9(8.2)$ & $3(2.7)$ \\
\hline $\begin{array}{l}\text { Receiving Influenza vaccine before MS } \\
\text { onset (yes/no) }\end{array}$ & $18(16.4)$ & $32(29.1)$ \\
\hline $\begin{array}{l}\text { Self-reported vitamin D deficiency } \\
\text { (yes/no) }\end{array}$ & $83(75.5)$ & $76(69.1)$ \\
\hline
\end{tabular}

\section{Multivariable conditional logistic regression model}

Final multivariable conditional logistic regression model showed that after adjusting for the effect of educational level, the cases compared to controls were more likely to have had a positive family history of $\mathrm{MS}\left(\mathrm{mOR}_{\mathrm{adj}}=5.1\right.$; 95\% CI: 2.1-12.4; $p<0.001)$. Additionally, after taking into account the effect of educational level, cases compared to control were significantly less likely to have had received influenza virus $A$ and $B$ vaccine before MS onset $\left(\mathrm{mOR}_{\mathrm{adj}}=0.4 ; 95 \% \mathrm{CI}: 0.2-0.8 ; p=0.010\right)$ (Table 4).

\section{Discussion}

This matched case-control study examined the association of various risk factors and MS risk in Kuwait. The multivariable conditional logistic regression model showed that family history of MS was significantly and independently associated with MS in this study. Family history is an established risk factor for MS [1, 3, 7, 11], seemingly through enhanced susceptibility resulting from gene-gene interactions in human leukocyte antigen (HLA) system $[11,23]$. While a clear association with variation in HLA 
Table 3 Univariable conditional logistic regression analyses of risk factors associated with multiple sclerosis in a case-control study in Kuwait

\begin{tabular}{|c|c|c|c|}
\hline Variables $^{\mathrm{a}}$ & Matched OR & $95 \% \mathrm{Cl}$ & $p$-value \\
\hline Country of birth (Kuwait vs. abroad) & 3.5 & $0.7-16.8$ & 0.118 \\
\hline $\begin{array}{l}\text { Education level at MS onset ( } \leq \text { high school vs. }>\text { high } \\
\text { school) }\end{array}$ & 2.7 & $1.0-6.8$ & 0.040 \\
\hline Marital status at MS onset (ever vs. never) & 1.5 & $0.8-2.9$ & 0.240 \\
\hline \multicolumn{4}{|l|}{ Household monthly income (KD) } \\
\hline$\leq 600$ & 1.0 & - & \\
\hline $601-1200$ & 1.0 & $0.4-2.8$ & 0.959 \\
\hline$>1200$ & 0.8 & $0.3-2.1$ & 0.703 \\
\hline \multicolumn{4}{|l|}{ BMI } \\
\hline$<25$ & 1.0 & - & \\
\hline $25-29.9$ & 1.0 & $0.5-2.1$ & 0.964 \\
\hline$\geq 30$ & 1.2 & $0.6-2.7$ & 0.596 \\
\hline Birth order (2nd or more vs. 1st) & 1.1 & $0.6-2.2$ & 0.732 \\
\hline \multicolumn{4}{|l|}{ Parents relationship } \\
\hline Un-related & 1.0 & - & \\
\hline First degree cousins & 0.9 & $0.5-1.9$ & 0.862 \\
\hline Second degree cousins & 0.5 & $0.2-1.2$ & 0.109 \\
\hline Presence during Gulf war (yes vs. no) & 0.5 & $0.3-1.0$ & 0.062 \\
\hline Family history of MS (yes vs. no) & 3.5 & $1.6-7.7$ & 0.002 \\
\hline Tobacco smoking status (yes vs. no) & 2.2 & $0.8-6.3$ & 0.144 \\
\hline $\begin{array}{l}\text { Childhood exposure to environmental tobacco smoke } \\
\text { (yes vs. no) }\end{array}$ & 0.7 & $0.4-1.2$ & 0.210 \\
\hline Regular passive smoking (yes vs. no) & 1.0 & $0.5-1.8$ & 0.876 \\
\hline Tonsillectomy before MS onset (yes vs. no) & 1.1 & $0.4-2.9$ & 0.808 \\
\hline Appendectomy before MS onset (yes vs. no) & 3.0 & $0.8-11.1$ & 0.099 \\
\hline Receiving Influenza vaccine before MS onset (yes vs. no) & 0.5 & $0.2-0.9$ & 0.030 \\
\hline Self-reported vitamin D deficiency (yes vs. no) & 1.4 & $0.8-2.6$ & 0.277 \\
\hline
\end{tabular}

${ }^{a}$ Distribution of area of residence, number of siblings, chicken pox, mumps and measles infections, receiving Hepatitis B virus vaccine and measles-mumps-rubella vaccine, regular exposure to solvents and history of autoimmune diseases (i.e. inflammatory bowel disease, systemic lupus erythematosus, rheumatoid arthritis, Graves' disease) were not significantly different between MS cases and their matched controls

has been established in MS, which explains up to $10.5 \%$ of the genetic variance of underlying risk, other genetic regions beyond HLA also have been shown to enhance the susceptibility to MS [24]. In multivariable analysis, vaccination against influenza $A$ and $B$ viruses showed a protective effect against MS risk. To the best of our knowledge, a non-specific protective effect of influenza A and B viruses' vaccine against MS development has not been shown previously. This association possibly could be coincidental with no biological causal link [25]. Nonetheless, observations of autoimmune diseases in animal models suggest that some infections may enhance the risk while others may contribute to prevent autoimmune diseases, showing diversity in the host immune response [26]. Furthermore, it is difficult to assess the effect of influenza vaccine on MS risk since the antigenic composition of seasonal influenza vaccines changes annually depending upon the prevalent influenza virus serotypes [27]. Further studies are needed to better understand the role of influenza vaccine in MS risk observed in this study.

Table 4 Multivariable conditional logistic regression model of risk factors associated with multiple sclerosis in a case-control study in Kuwait

\begin{tabular}{lllr}
\hline Risk factor & Adjusted matched OR & $95 \% \mathrm{Cl}$ & $p$-value \\
\hline Family history of MS (yes vs. no) & 5.1 & $2.1-12.4$ & $<0.001$ \\
Influenza vaccination (yes vs. no) & 0.4 & $0.2-0.8$ & 0.010
\end{tabular}

"Model is adjusted for 'education level' i.e. $\leq$ high school vs. > high school 
The findings of this study revealed that tobacco smoking did not show a statistically significant association (active, and/or environmental exposure to tobacco smoke) with MS status. The results of this study are consistent with those of few earlier studies conducted in Kuwait, which did not reveal significant relationship between tobacco smoking and MS risk [3, 7, 28]. However, elsewhere, tobacco smoking has been shown repeatedly as a significant risk factor for increased MS risk [1, 9-12]. Furthermore, it has been previously shown that the effect of tobacco smoke on MS risk is genetically-dependent, and genetic compositions vary across the populations $[9,29,30]$. A concurrent and/ or alternate explanation may be that tobacco smoking both active and passive is highly prevalent in general population in Kuwait that posed us a difficulty in segregation and measuring the exposure to active tobacco smoking and to environmental tobacco smoke. Future studies should consider assessing the exposure to tobacco smoke by cotinine testing (saliva or urine samples) of both cases and controls in Kuwait.

Several variables were not statistically significantly associated with MS status such as country of birth, area of residence, level of education, marital status, socioeconomic status and BMI at time of disease onset, number of siblings, birth order and degree of relationship of parents. Some other previously reported important risk factors for MS including regular exposure to solvents, history of tonsillectomy, appendectomy and self-reported vitamin D deficiency $[1,10]$, did not attain statistical significance either because these factors indeed did not pose a substantial MS risk in our setting or probably due to low study power regarding these exposures, thus need further evaluation.

We also did not find a significant association between hepatitis $\mathrm{B}$ virus and measles-mumps-rubella vaccination status. These findings are consistent with those reported in systematic reviews of relationship between MS onset and vaccination against several infections such as measlesmumps-rubella, hepatitis B virus, influenza virus, human papilloma virus, diphtheria, tetanus, pertussis, or meningococcal disease [25, 27].

Few limitations of this study should be considered. First, recall bias is an inherent limitation of case-control study design, cases might have remembered exposure to various risk factors better than the controls. However, the time window for ascertaining exposures was the same for matched controls and cases. Secondly, the possibility of under-reporting of smoking among MS patients especially females, which could be driven by feeling of guilt or social implications of admitting smoking in the presence of a relative or family member. Thirdly, smoking is less common among females, whom composed most cases, therefore a larger sample size might be needed to assess the association between smoking and MS risk.

\section{Conclusions}

This study showed that family history of MS was significantly associated with an increased MS risk, whereas, vaccination against influenza A and B viruses offered significant protection against MS. Further studies are indicated to verify this observed and previously un-reported association. Furthermore, question remained unanswered is why tobacco smoking continues to have a non-significant relationship with MS in this and previous studies reported from Kuwait as opposed to what has been consistently reported elsewhere. Future studies need to consider this aspect perhaps through objective measurement of exposure to tobacco smoke in the Middle Eastern countries including Kuwait.

\section{Supplementary information}

Supplementary information accompanies this paper at https://doi.org/10. 1186/s12883-020-01635-1.

Additional file 1. Questionnaire for Case

Additional file 2. Questionnaire for Control

\section{Abbreviations}

Cl: Confidence intervals; EBV: Epstein-Barr virus; mOR: Matched odds ratio; mORadj: Adjusted mOR; MRI: Magnetic resonance imaging; MS: Multiple sclerosis

Acknowledgements

We thank the study participant for their understanding and participation in this study. Authors also express their gratitude to Mr. Joseph Edison Gomez, for his assistance in data managment and analysis.

\section{Authors' contributions}

HM Protocol development, data collection and analysis, prepared the first draft of the article. SA Conception of the study, proposal development, data analysis and review of article drafts. RA Facilitated data acquisition, reviewed proposal and questionnaire, data interpretation and review of article drafts. HM, SA, RA: All approved the final submitted and revised versions of the manuscript.

Funding

This study received no specific funding from any source.

\section{Availability of data and materials}

The datasets used and analysed during the current study are available from the corresponding author on reasonable request.

\section{Ethics approval and consent to participate}

Ethical approval of the study protocol was granted by Health Sciences Center Ethical Committee, Kuwait University and The Standing Committee for Coordination of Health and Medical Research, Ministry of Health, Kuwait. Written consent was obtained from each study participant after explaining the aims and potential benefits of the study, length of questionnaire and time required to answer all the questions.

Consent for publication

Not applicable

\section{Competing interests}

The authors declare that they have no competing interests.

\section{Author details}

'Department of Community Medicine and Behavioural Sciences, Faculty of Medicine, University of Kuwait, PO Box 24923, 13110 Safat, Kuwait. ²Division of Neurology, Department of Medicine, Amiri Hospital, Arabian Gulf Street, 13041 Sharq, Kuwait. 
Received: 1 August 2019 Accepted: 4 February 2020

Published online: 21 February 2020

\section{References}

1. Ramagopalan SV, Dobson R, Meier UC, Giovannoni G. Multiple sclerosis: risk factors, prodromes, and potential causal pathways. Lancet Neurol. 2010;9(7): 727-39. https://doi.org/10.1016/S1474-4422(10)70094-6.

2. Marrie RA, Horwitz RI. Emerging effects of comorbidities on multiple sclerosis. Lancet Neurol. 2010;9(8):820-8. https://doi.org/10.1016/S14744422(10)70135-6.

3. Al-Afasy HH, Al-Obaidan MA, Al-Ansari YA, Al-Yatama SA, Al-Rukaibi MS, Makki NI, et al. Risk factors for multiple sclerosis in Kuwait: a populationbased case-control study. Neuroepidemiology. 2013;40(1):30-5. https://doi. org/10.1159/000341240.

4. Federation. MSI: Atlas of MS 2013: mapping multiple sclerosis around the world. Multiple Sclerosis International Federation London; 2013.

5. Akhtar S, Alroughani R, Ahmed SF, Al-Hashel JY. Retrospective cohort study of gender differential in risk of multiple sclerosis in Kuwait. Neuroepidemiology. 2016;46(3):203-8. https://doi.org/10.1159/000444185.

6. Alroughani R, Ahmed SF, Al-Hashel J. Demographics and clinical characteristics of multiple sclerosis in Kuwait. Eur Neurol. 2014;72(3-4):1815. https://doi.org/10.1159/000362270.

7. Al-Shammri SN, Hanna MG, Chattopadhyay A, Akanji AO. Sociocultural and Demographic Risk Factors for the Development of Multiple Sclerosis in Kuwait: A Case - Control Study. PLoS One. 2015;10(7):e0132106. https://doi. org/10.1371/journal.pone.0132106.

8. Akhtar S, Alroughani R, Al-Shammari A, Al-Abkal J, Ayad Y. Month of birth and risk of multiple sclerosis in Kuwait: a population-based registry study. Multiple Sclerosis (Houndmills, Basingstoke, England). 2015;21(2):147-54. https://doi.org/10.1177/1352458514541578.

9. Hedstrom AK, Olsson T, Alfredsson L. Smoking is a major preventable risk factor for multiple sclerosis. Multiple Sclerosis (Houndmills, Basingstoke, England). 2015. https://doi.org/10.1177/1352458515609794.

10. Belbasis L, Bellou V, Evangelou E, loannidis JP, Tzoulaki I. Environmental risk factors and multiple sclerosis: an umbrella review of systematic reviews and meta-analyses. Lancet Neurol. 2015;14(3):263-73. https://doi.org/10.1016/ s1474-4422(14)70267-4

11. Zhang P, Wang R, Li Z, Wang Y, Gao C, Lv X, et al. The risk of smoking on multiple sclerosis: a meta-analysis based on 20,626 cases from case-control and cohort studies. PeerJ. 2016;4:e1797. https://doi.org/10.7717/peerj.1797.

12. Palacios N, Alonso A, Bronnum-Hansen $\mathrm{H}$, Ascherio A. Smoking and increased risk of multiple sclerosis: parallel trends in the sex ratio reinforce the evidence. Ann Epidemiol. 2011;21(7):536-42. https://doi.org/10.1016/j. annepidem.2011.03.001.

13. Manouchehrinia A, Tench CR, Maxted J, Bibani RH, Britton J, ConstantinesCu CS. Tobacco smoking and disability progression in multiple sclerosis: United Kingdom cohort study. Brain. 2013;136(Pt 7):2298-304. https://doi.org/10. 1093/brain/awt139.

14. Manouchehrinia A, Weston M, Tench CR, Britton J, Constantinescu CS. Tobacco smoking and excess mortality in multiple sclerosis: a cohort study. J Neurol Neurosurg Psychiatry. 2014;85(10):1091-5. https://doi.org/10.1136/ jnnp-2013-307187.

15. Alshubaili AF, Alramzy K, Ayyad YM, Gerish Y. Epidemiology of multiple sclerosis in Kuwait: new trends in incidence and prevalence. Eur Neurol. 2005;53(3):125-31. https://doi.org/10.1159/000085556.

16. Alroughani R, Ahmed SF, Behbahani R, Khan R, Thussu A, Alexander KJ, et al. Increasing prevalence and incidence rates of multiple sclerosis in Kuwait. Multiple Sclerosis (Houndmills, Basingstoke, England). 2014;20(5):543-7. https://doi.org/10.1177/1352458513504328.

17. Ministry of Health in Kuwait, Eastern Mediterranean Approach for Control of Non-Communicable diseases (EMAN). Survey for risk factors for chronic non-communicable diseases. WHO.int. 2008/090. http://www.who.int/chp/ steps/STEPS_Report_Kuwait.pdf. Accessed 8 Nov 2019.

18. Maziak W, Taleb ZB, Bahelah R, Islam F, Jaber R, Auf R, et al. The global epidemiology of waterpipe smoking. Tob Control. 2015;24(Suppl 1):i3-i12. https://doi.org/10.1136/tobaccocontrol-2014-051903.

19. Polman $\mathrm{CH}$, Reingold SC, Banwell B, Clanet M, Cohen JA, Filippi M, et al. Diagnostic criteria for multiple sclerosis: 2010 revisions to the McDonald criteria. Ann Neurol. 2011;69(2):292-302. https://doi.org/10.1002/ana.22366.
20. Global Adult Tobacco Survey Collaborative Group. Tobacco Questions for Survey: A Subset of Key Questions From the Global Adult Tobacco Survey (GATS). 2nd ed; 2011.

21. Avila-Tang E, Elf JL, Cummings KM, Fong GT, Hovell MF, Klein JD, et al. Assessing secondhand smoke exposure with reported measures. Tob Control. 2013;22(3):156-63. https://doi.org/10.1136/tobaccocontrol-2011050296.

22. Lachin JM. Sample size evaluation for a multiply matched case-control study using the score test from a conditional logistic (discrete Cox PH) regression model. Stat Med. 2008;27(14):2509-23. https://doi.org/10.1002/ sim.3057.

23. Moutsianas L, Jostins L, Beecham AH, Dilthey AT, Xifara DK, Ban M, et al. Class II HLA interactions modulate genetic risk for multiple sclerosis. Nat Genet. 2015;47(10):1107-13. https://doi.org/10.1038/ng.3395.

24. Hollenbach JA, Oksenberg JR. The immunogenetics of multiple sclerosis: a comprehensive review. J Autoimmun. 2015;64:13-25. https://doi.org/10. 1016/j.jaut.2015.06.010.

25. Williamson EML, Chahin S, Berger JR. Vaccines in Multiple Sclerosis. Curr Neurol Neurosci Rep. 2016;16(4):36. https://doi.org/10.1007/ s11910-016-0637-6.

26. Ascherio A, Munger KL. Environmental risk factors for multiple sclerosis. Part I: the role of infection. Ann Neurol. 2007;61(4):288-99. https://doi.org/10. 1002/ana.21117.

27. Mailand MT, Frederiksen JL. Vaccines and multiple sclerosis: a systematic review. J Neurol. 2016. https://doi.org/10.1007/s00415-016-8263-4.

28. Al-Temaimi R. Dietary and lifestyle habits of multiple sclerosis patients from Kuwait. Unpublished Report 2016.

29. Hedstrom AK, Sundqvist E, Baarnhielm M, Nordin N, Hillert J, Kockum I, et al. Smoking and two human leukocyte antigen genes interact to increase the risk for multiple sclerosis. Brain. 2011;134(Pt 3):653-64. https://doi.org/10. 1093/brain/awq371.

30. Briggs FB, Acuna B, Shen L, Ramsay P, Quach H, Bernstein A, et al. Smoking and risk of multiple sclerosis: evidence of modification by NAT1 variants. Epidimiology. 2014;25(4):605-14. https://doi.org/10.1097/ede. 0000000000000089.

\section{Publisher's Note}

Springer Nature remains neutral with regard to jurisdictional claims in published maps and institutional affiliations.

Ready to submit your research? Choose BMC and benefit from:

- fast, convenient online submission

- thorough peer review by experienced researchers in your field

- rapid publication on acceptance

- support for research data, including large and complex data types

- gold Open Access which fosters wider collaboration and increased citations

- maximum visibility for your research: over $100 \mathrm{M}$ website views per year

At BMC, research is always in progress.

Learn more biomedcentral.com/submissions 